\title{
DIE METING VAN DIE GELYKTYDIGE HANTERING VAN TEENSTRYDIGE EN DUBBELSINNIGE INLIGTING AS KRITIEKE EIENSKAP IN 'N VERSKEIDENHEID VAN BEROEPE
}

\author{
W.S. DE VILLIERS
}

DEPARTEMENT BEDRYFSIELKUNDE

UNIVERSITEIT VAN STELLENBOSCH
I. VAN W. RAUBENHEIMER

DEPARTEMENT BEDRYFSIELKUNDE

RANDSE AFRIKAANSE UNIVERSITEIT

\section{ABSTRACT}

\begin{abstract}
Since very little is known about how to deal with conflicting and ambiguous information as a work attribute an attempt was made to define this particular construct and subject it to empirical research. An instrument (the in basket exercise) was developed to measure employees' efficiency in dealing with conflicting and ambiguous information. This instrument together with instruments for measuring a number of related traits were administered to 468 subjects. It was determined that the capacity to deal with conflicting and ambiguous information has a certain relationship with intelligence and sensory cognitive judgement. No relationship could be found with certain personality traits. In all probability a separate construct is indicated by this research.
\end{abstract}

Een van die hoekstene waarop effektiewe personeelbestuur rus, is die wetenskaplike keuring van mannekrag. Met wetenskaplike keuring word bedoel dat die prosedures en meetmiddels wat in die keuringsproses gebruik word volgens algemeen aanvaarde wetenskaplike beginsels ontwikkel en geïmplimenteer word.

Hoewel daar in Suid-Afrika heelwat vordering gemaak is op die terrein van wetenskaplike personeelkeuring blyk dit tog asof die grondbeginsels van keuring nie altyd reg verstaan word en die vereistes van wetenskaplike keuring nie altyd nagekom word nie (Lätti, 1977).

Vir die daarstelling van enige doeltreffende stelsel van keuring van werknemers is dit nodig om 'n deeglike insig te verkry in die ter saaklike posvereistes; met ander woorde daar

\footnotetext{
* Versoeke vir afskrifte moet aan die eerste skrywer gerig word.
} 
moet vasgestel word watter vermoëns die werknemer moet besit ten einde 'n suksesvolle posbekleër te wees. Verder is dit nodig om geskikte meetinstrumente daar te stel vir die meting van sodanige geïdentifiseerde vermoëns en dan moet vasgestel word of die gekose meetinstrumente inderdaad funksioneer as geldige voorspellers van uiteindelike werksukses.

Die beginpunt, en in vele opsigte die basis, van die wetenskaplike keuringsproses is die bepaling van die vermoëns of eienskappe wat 'n suksesvolle werknemer in 'n bepaalde pos moet hê. Vermoëns wat in bepaalde werksverbande vereis word, is egter nie altyd duidelik omskryfbaar of definieerbaar nie sodat dit opsigself die onderwerp vir verdere navorsing kan word.

Een van die werksvermoëns of attribute wat herhaaldelik in navorsingsprojekte deur Raubenheimer, Augustyn en De Villiers (1979) met behulp van die PAQ posontledingstegniek (Marquardt en McCormick, 1972; Marquardt en McCormick, 1973; McCormick, Jeanneret en Mecham 1969) geïdentifiseer is, is die vermoë om teenstrydige en dubbelsinnige inligting te hanteer.

Aangesien daar geen of weinig gedokumenteerde inligting oor hierdie bepaalde gedragsverskynsel bestaan, was dit die doelstelling van die navorsing wat hier gerapporteer word om (a) die vermeende konstruk konseptueel te omlyn en (b) om 'n instrument te ontwikkel om die konstruk te meet.

In sy meer primêre vorm wil dit voorkom asof die hantering van teenstrydige en dubbelsinnige inligting te make het met die hantering van konflik en meer bepaald die oplossing van probleemsituasies.

Perloff (1979) in sy siening omtrent die kies van alternatiewe in 'n probleemsituasie wys daarop dat doeltreffende optrede nie soseer betrekking het op die keuse van alternatiewe nie - maar wel op die identifisering van uitvoerbare optredes of aksies. Sodanige aksie, wanneer dit ten uitvoer gebring word, sal dan deel vorm van 'n optrederigting waarvan die gevolge of implikasies beter is as enige ander alternatiewe optrede.

Indien die konseptuele brug geslaan sou kon word tussen konflik, probleemoplossing en teenstrydige, dubbelsinnige inligting, impliseer die doeltreffende hantering van teenstrydige en dubbelsinnige inligting dat 'n individu met sodanige vermoë doeltreffend sal kan redeneer omtrent die bestaan van verskille in 'n situasie, dat hy sal kan insien dat daar byvoorbeeld 'n gemeenskaplike basis kan wees en redes kan insien vir die aanwesigheid daarvan en dat hy in so 'n situasie die bes moontlike alternatiewe optredes sal kan identifiseer en ten uitvoer bring. 
Uit 'n praktiese werksituasie-oogpunt gesien impliseer hierdie attribuut die vermoë om teenstrydige, en dubbelsinnige inligting op 'n objektiewe wyse krities te hanteer, te verwerk en besluitneming daarop te baseer. Die klem val dus op die kalme hantering van die inligting wat op 'n bepaalde tyd vinnig instroom (Munn, 1961; Zaleznik \& Moment, 1964).

Voorbeelde waar sodanige vermoë ter sprake kom sou wees wanneer 'n masjienoperateur moet reageer op verskillende bronne van informasie (byvoorbeeld meters, waarskuwingsligte, geluide, ens.) wat gelyktydig onder sy aandag kom. Die een bron van informasie kan betrekking hê op die spoed waarteen die masjien fungeer, die ander op die temperatuur en nog 'n bron kan betrekking hê op die kwaliteit van die klaarproduk. Te midde van hierdie gelyktydige instroming van informasie met verskillende betekenisse word van die masjienoperateur verwag om kalm en beredeneerd op te tree, die informasie te verwerk en 'n besluit op grond daarvan te neem sodat 'n aanvaarbare peil van werkverrigting gehandhaaf kan word.

So ook kan die klerklike- of bestuursamptenaar in 'n organisasie hom in 'n situasie bevind waar hy te make het met data of informasie wat instroom en wat botsend kan wees. Hy sou byvoorbeeld opdragte of inligting kon ontvang waarin van hom verwag word om verskillende aktiwiteite op dieselfde tydstip uit te voer - byvoorbeeld ewe belangrike dagboekafsprake op dieselfde dag en datum na te kom, bywoning van verskillende vergaderings op dieselfde tyd, ensovoorts. Ook in hierdie situasie word van 'n posbekleër verwag om die vermoë te hê om die situasies effektief te kan hanteer en die regte besluit te neem.

Teen die agtergrond van die voorafgaande bespreking blyk dit dus dat die vermoë om teenstrydige en dubbelsinnige inligting te hanteer betrekking het op die kalme en doeltreffende hantering van inligting wat op 'n bepaalde tyd vinnig instroom. In die werksituasie sal dit beteken dat 'n posbekleër die vermoë sal hê om inligting wat soms verwarrend of botsend is te kan evalueer, gemeenskaplike elemente te kan identifiseer en klassifiseer en 'n doeltreffende besluit te neem om 'n probleemsituasie op te los.

Afgesien van die meer operasionele omlyning van die begrip, was dit ook nodig om aanverwante, meer bekende konstrukte in die literatuur na te gaan wat moontlik groter duidelikheid kan bring oor die dinamiek daarvan.

Sekere determinante van gedrag skyn verband te hou met die vermoë om teenstrydige en dubbelsinnige inligting te hanteer. 'n Sekere intellektuele vermoë word klaarblyklik vereis 
wat sal bydra tot die vinnige ontleding van 'n probleemsituasie (Munn, 1961; Tyler, 1965). Die persoon wat teenstrydige en dubbelsinnige inligting doeltreffend kan hanteer openbaar blykbaar 'n tolleransie vir sodanige dubbelsinnigheid (Adorno, Erenkel-Brunswik, Levinson en Sanford, 1950; Brown, 1965).

Wat persoonlikheid betref wil dit dus voorkom asof dit 'n neratiewe verband behoort te hê met persoonlikheidskenmerke soos angstigheid, rigiditeit en dominansie.

Sensories kognitiewe oordeel wat betrekking het op die doeltreffende diskriminering tussen verskillende stimuli skyn ook 'n belangrike eienskap te wees van die persoon wat teenstrydige en dubbelsinnige inligting doeltreffend hanteer (Krech, Curtchfield en Ballachey, 1962).

Sekere kognitiewe style het na alle waarskynlikheid ook betrekking op die vermoë om teenstrydige en dubbelsinnige inligting te hanteer. Die volgende style skyn op grond van hul omskrywings in die literatuur (De Jager, 1979) sodanig verbandhoudend te wees:

- Veldafhanklikheid - onafhanklikheid

- Gelykmaking en verskerping

- Verdraagsaamheid vir onrealistiese ondervindinge

- Kategoriewydte

- $\quad$ Buigsame en beperkte kontrole

- $\quad$ Konseptuele style

- $\quad$ Refleksie impulsiwiteit

Diepte-oriëntasie soos omskryf deur De Jager (1979) hou waarskynlik ook verband met die vermoë om teenstrydige en dubbelsinnige inligting te hanteer.

\section{DIE METING VAN DIE VERMÖ̈ OM TEENSTRYDIGE EN DUBBELSINNIGE INLIGTING TE HANTEER}

Uit die voorafgaande bespreking van sekere moontlike gedragskorrelate van die vermoë om teenstrydige en dubbelsinnige inligting te hanteer blyk dit duidelik dat nie een van die korrelate naby genoeg daaraan kom sodat enige bestaande meetinstrument oorgeneem of aangepas kon word om die gepostuleerde konstruk te meet nie.

Die ontwikkeling van 'n pasgemaakte meetinstrument was dus die enigste uitweg. Bo en behalwe dat so 'n meetinstrument aan die teoretiese konstrukvereistes moes voldoen, moes 
dit ook 'n praktiese inslag hê sodat dit moontlik bruikbaar kon wees in praktiese personeelbestuursituasies.

Met ingang van al die voorafgaande inligting, het die keuse op die ontwikkeling van 'n posmandjie geval.

\section{Die posmandjie as meetmiddel}

Die posmandjie is in werklikheid 'n prestasietoets aangesien die kandidaat in 'n situasie soortgelyk aan die werklike werksituasie geplaas word en 'n beoordeling gemaak word van die mate van effektiwiteit waarmee aan die vereistes van die gestelde taak voldoen word. In 'n tipiese posmandjietoets word 'n kandidaat gekonfronteer met 'n versameling van realistiese items wat betrekking het op 'n sekere werk (byvoorbeeld daaglikse verslae, telegramme, navrae, sosiale afsprake, klagtes, ensovoorts). Die taak van die kandidaat (of applikant) is om deur die betrokke items te werk en elk te hanteer asof hy in 'n werklike situasie optree. Sy response en of besluite stel hy op skrif met, indien vereis, ook motiverings waarom hy so reageer of besluit. Die response word beoordeel deur opgeleide beoordelaars wat in hul beoordeling 'n aantal dimensies as basis gebruik byvoorbeeld (i) die neem van besluite en die oorgaan tot optrede versus die uitstel van 'n besluit of optrede (ii) hoë uitset versus lae uitset. (iii) onafhanklike optrede versus die kry van advies en leiding van ander. Dit is dus ook duidelik dat die inhoud van 'n posmandjie aangepas kan word by 'n spesifieke behoefte of situasie.

Ten spyte van sekere tekortkominge van die posmandjie as meetinstrument, byvoorbeeld dat dit soms afhanklik kan wees van persoonlikheidsfaktore en dat die prestasie in verskillende posmandjies vir dieselfde werk kan fluktueer (Orpen, 1979; pp. 55 en 56) het dit tog heelwat voordele. Sommige studies toon dat dit in sekere situasies 'n hoë voorspellingsgeldigheid het (Orpen, 1979, p. 56). Vakbonde het nie wesenlike beswaar teen sodanige werksrelevante toetsing nie en die tipe toetsing het ook getoon beter voorspellers te wees van latere werksukses as vaardigheids- en persoonlikheidstoetse (Asher en Sciarrino, 1974, pp. 519-533; Campion, 1972 pp. 40-44; Miner \& Miner, 1977, pp. 3211324; Meyer, 1970, pp. 297-307).

Teen hierdie agtergrond is daar besluit dat die posmandjie hom daartoe leen om items in te bou wat betrekking sal hê op die vermoë om teenstrydige en dubbelsinnige inligting 
gelyktydig in die werksituasie te hanteer. Sodanige posmandjie tesame met 'n antwoordblad waarop die kandidaat sy besluite en response kan aanbring is gevolglik saamgestel.

\section{METODE}

Die onderhawige studie kan beskou word as 'n konstrukvalideringstudie. Dit gaan dus om die omlyning van die gepostuleerde konstruk, naamlik die vermoë om teenstrydige en dubbelsinnige inligting te hanteer. Die strategie om die konstruk te omlyn kom daarop neer dat teenstrydige en dubbelsinnige inligting (gereflekteer deur tellings op die posmandjie) telkens gekorreleer word met meetmiddels van gedragsvorme wat in die voorafgaande gedeeltes uitgelig is as moontlik verbandhoudend met tellings op die posmandjie. Die rigting van die verband word in die onderstaande hipoteses gestipuleer.

\section{Hipoteses}

$\mathrm{H}_{1}$ Dat daar 'n beduidend positiewe verband bestaan tussen die hantering van teenstrydige en dubbelsinnige inligting en intellektuele vermoё.

$\mathrm{H}_{2}$ Dat daar 'n beduidend positiewe verband bestaan tussen die vermoë om teenstrydige en dubbelsinnige inligting te hanteer en sensories kognitiewe oordeel.

$\mathrm{H}_{3}$ Dat daar ' $\mathrm{n}$ beduidend negatiewe verband bestaan tussen die vermoë om teenstrydige en dubbelsinnige inligting te hanteer en angstigheid as persoonlikheidskenmerk.

$\mathrm{H}_{4}$ Dat daar ' $\mathrm{n}$ beduidend negatiewe verband bestaan tussen die vermoë om teenstrydige dubbelsinnige inligting te hanteer en rigiditeit as persoonlikheidskenmerk.

$\mathrm{H}_{5}$ Dat daar ' $\mathrm{n}$ beduidend negatiewe verband bestaan tussen die vermoë om teenstrydige en dubbelsinnige inligting te hanteer en dominansie as persoonlikheidskenmerk.

$\mathrm{H}_{6}$ Dat daar ' $\mathrm{n}$ beduidend positiewe verband bestaan tussen die vermoë om teenstrydige en dubbelsinnige inligting te hanteer en diepte-oriëntasie.

$\mathrm{H}_{7}$ Dat daar ' $\mathrm{n}$ beduidend positiewe verband bestaan tussen die vermoë om teenstrydige en dubbelsinnige inligting te hanteer en die belangstelling om met mense te werk. 


\section{Proefpersone}

Vir die doeleindes van die omlyning van die konstruk is daar van twee groepe proefpersone gebruik gemaak. Die eerste groep het bestaan uit 86 finalejaar handelstudente waarvan die ouderdomme gewissel het van 20 tot 25 jaar. Ten einde die ondersoek ook van toepassing te maak op 'n praktiese bedryfsituasie is gebruik gemaak van 382 klerklik administratiewe werkers by 'n groot versekeringsmaatskappy.

\section{Meetinstrumente}

By die eerste groep (studente) is die volgende meetinstrumente gebruik vir die meting van die onderskeie vermoëns:

\begin{tabular}{|l|l|}
\hline \multicolumn{1}{|c|}{ VERMOË } & \multicolumn{1}{c|}{ MEETINSTRUMENT } \\
\hline Intelligensie & $\begin{array}{l}\text { Die Hoëvlakbattery van die NIPN (Verstandelike } \\
\text { Helderheid). } \\
\text { Die Gottschaldt figuretoets } \\
\text { Persoonlikheid }\end{array}$ \\
$\begin{array}{l}\text { Die Suid-Afrikaanse Persoonlikheidsvraelys (SAPV) } \\
\text { met subtoetse: sosiale responsiwitiet, angstigheid, } \\
\text { vyandigheid, rigiditiet en dominansie. }\end{array}$ \\
$\begin{array}{l}\text { Diepte-Oriëntasie hantering van teenstrydige en dubbelsinnige } \\
\text { inligting. }\end{array}$ & $\begin{array}{l}\text { Die RD-Diepte-Oriëntasievraelys (De Jager, 1979). } \\
\text { Die Posmandjie }\end{array}$ \\
\hline
\end{tabular}

By die tweede groep (klerklik administratiewe werkers) is die volgende meetinstrumente gebruik vir die meting van die onderskeie vermoëns:

\begin{tabular}{|l|l|}
\hline \multicolumn{1}{|c|}{ VERMOË } & \multicolumn{1}{|c|}{ MEETINSTRUMENT } \\
\hline $\begin{array}{l}\text { Intellektuele vermoë } \\
\text { Oriëntasie tot mense en lewelose dinge }\end{array}$ & $\begin{array}{l}\text { NIPN Hoëvlakbattery (Verstandelike Helderheid). } \\
\text { Radef Belangstellingsvraelys, ontwikkel deur } \\
\text { Raubenheimer, Augustyn, De Villiers en Fick (1978). } \\
\text { Gottschaldt figuretoets }\end{array}$ \\
$\begin{array}{l}\text { Sie hantering van teenstrydige en dubbelsinnige } \\
\text { inligting. }\end{array}$ & Die Posmandjie \\
\hline
\end{tabular}

\section{Prosedure}

Wat die Hoëvlakbattery van die NIPN, die Suid-Afrikaanse Persoonlikheidsvraelys van die NIPN, die Gottschaldt figuretoets, die RD-Diepte-oriëntasievraelys en die Radef Belangstellingsvraelys betref is die instruksies van die betrokke opstellers van hierdie instrumente gevolg. 


\section{Die Posmandjie toetsprosedure}

Toetslinge is versoek om die agtergrondinligting van die Posmandjie deur te lees en dan onmiddellik voort te gaan met die oefening. Die tydsbeperking was 25 minute.

Nadat die toetslinge die Posmandjie voltooi het is 'n opsommingsvorm aan elkeen verskaf met die versoek dat hulle daardie respons wat die naaste aan hulle persoonlike oplossing blyk te wees, duidelik met 'n kruis in die toepaslike blokkie moes merk.

Daar is duidelike opdrag gegee aan toetslinge dat hulle op hierdie stadium geen veranderings aan hulle voltooide Posmandjie mag aanbring nie.

Hoewel die Posmandjie met ' $n$ nasienmasker nagesien sou kon word is daar besluit om dit liefs met die hand na te sien aangesien sommige response 'n mate van interpretasie kan vereis. 'n Punt is vir elke korrekte item toegeken met 'n maksimum van sewe punte.

\section{RESULTATE}

\section{Groep 1}

Met behulp van die SAPV kon 5 tellings van elkeen van die toetslinge verkry word vir die onderskeie persoonlikheidsvelde naamlik sosiale responsiwiteit, angstigheid, vyandigheid, rigiditeit en dominansie. Hierdie vyf tellings tesame met die tellings behaal op die ander vier meetinstrumente is gebruik om 'n Pearson produkmoment interkorrelasiematriks op te stel. Die resultate word in Tabel 1 uiteengesit.

\section{Groep 2}

Met behulp van die Radef Belangstellingsvraelys kon twee tellings van toetslinge verkry word wat onderskeidelik dui op 'n belangstelling vir werk met lewelose dinge (Radef 44) en 'n belangstelling vir werk met mense (Radef 61). Hierdie twee tellings tesame met die tellings behaal op die ander drie instrumente is gebruik om 'n Pearson produkmoment interkorrelasiematriks op te stel. Hierdie resultate word in Tabel 2 uiteengesit.

Op grond van die voorgaande resultate kon slegs die eerste twee gestelde hipoteses $\left(\mathrm{H}_{1}\right.$ en $\mathrm{H}_{2}$ ) nie sondermeer verwerp word nie. 'n Beduidende hoewel lae positiewe verband 
$(\mathrm{r}=, 26)$ is naamlik gevind tussen die vermoë om teenstrydige en dubbelsinnige inligting te hanteer en intellektuele vermoë (verstandelike helderheid) en tussen die vermoë om teenstrydige en dubbelsinnige inligting te hanteer en sensories kognitiewe oordeel $(r=, 19)$.

TABEL 1

INTERKORRELASIES TUSSEN VERSKILLENDE MEETINSTRUMENTE GEBASEER OP TOETSRESULTATE VAN 86 STUDENTE

\begin{tabular}{|c|c|c|c|c|c|c|c|c|c|c|}
\hline Meetinstrument & & G & $\mathrm{VH}$ & $\mathrm{P}$ & S & A & $\mathrm{V}$ & $\mathrm{R}$ & $\mathrm{D}$ & DO \\
\hline Gottschaldt figure & (G) & 1,00 &, $27 *$ &,- 02 &,- 10 &,- 11 &, 18 &, 12 &, 16 &, 08 \\
\hline $\begin{array}{l}\text { Verstandelike } \\
\text { helderheid }\end{array}$ & $(\mathrm{VH})$ & & 1,00 &, 19 &,- 13 &,- 16 &, 12 & ,02 &, 12 &,- 09 \\
\hline Posmandjie & $(\mathrm{P})$ & & & 1,00 &,- 05 &,- 22 & ,00 &,- 04 & ,09 &,- 08 \\
\hline $\begin{array}{l}\text { Sosiale responsi- } \\
\text { witeit }\end{array}$ & $(\mathrm{S})$ & & & & 1,00 &,$- 40 * *$ &,- 04 &,$- 26 *$ &, $46 * *$ & , $36 * *$ \\
\hline Angstigheid & (A) & & & & & 1,00 &,- 01 &, $37 * *$ &,$- 60 * *$ &,- 22 \\
\hline Vyandigheid & (V) & & & & & & 1,00 &,- 15 &, 21 &,$- 33 * *$ \\
\hline Rigiditeit & (R) & & & & & & & 1,00 &,$- 32^{*}$ &,- 01 \\
\hline Dominansie & (D) & & & & & & & & 1,00 &,$\dot{3} 7 * *$ \\
\hline Diepte-oriëntasie & (DO) & & & & & & & & & 1,00 \\
\hline
\end{tabular}

$* \mathrm{p}<, 01 \quad * * \mathrm{p}<, 001$

TABEL 2

INTERKORRELASIES TUSSEN VERSKILLENDE MEETINSTRUMENTE

GEBASEER OP TOETSRESULTATE VAN 382 KLERKLIK ADMINISTRATIEWE WERKERS

\begin{tabular}{|c|c|c|c|c|c|c|}
\hline Meetinstrument & & $(\mathrm{V} / \mathrm{H})$ & (G) & (P) & $\begin{array}{c}\text { (RADEF } \\
44)\end{array}$ & $\begin{array}{c}\text { (RADEF } \\
61)\end{array}$ \\
\hline Verstandelike helderheid & $(\mathrm{VH})$ & 1,00 &, $51 *$ & ,26* &,- 05 &, 03 \\
\hline Gottschaldt figure & $(G)$ & & 1,00 &, $19 *$ &, 04 & ,04 \\
\hline Posmandjie & (P) & & & 1,00 &,- 00 & ,01 \\
\hline Radef 44 belangstellingvraelys & (RADEF 44) & & & & 1,00 &,$- 36 *$ \\
\hline Radef 61 belangstellingvraelys & (RADEF 61) & & & & & 1,00 \\
\hline
\end{tabular}

$* \mathrm{p}<, 001$ 


\section{GEVOLGTREKKINGS EN AANBEVELINGS}

\section{Gevolgtrekkings}

Dit blyk dat die konstruk "die hantering van teenstrydige en dubbelsinnige inligting" verband hou met twee goed bekende konstrukte van menslike gedrag naamlik intellektuele vermoë (verstandelike helderheid) en diskriminasievermoë of sensories kognitiewe oordeel. Geen beduidende verband skyn te bestaan met persoonlikheidselemente soos rigiditeit, dominansie en angstigheid nie. Geen verband blyk ook te bestaan met diepte-oriëntasie en oriëntasie tot mense en tot lewelose dinge nie.

Die feit dat die vermoë om teenstrydige en dubbelsinnige inligting te hanteer met slegs twee van die begrippe wat ondersoek is verband hou dui nie noodwendig daarop dat daar geen sodanige konstruk bestaan nie. Guion $(1965$, p. 128) druk die probleem dan ook as volg uit: "Only in a limited sense may a specific statement of correlation be considered an operational definition of construct validity. In general, construct validity must be expressed as a judgement, inferred from the weight of research evidence gathered in many independent studies". Ook Cronbach en Meehl (in Guion, 1965) wys daarop dat 'n konstruk nie gedefinieer kan word deur 'n enkele gebeurde nie, maar met behulp van 'n netwerk van assosiasies en situasies waarin dit figureer. Hulle beklemtoon ook dat die proses van konstrukvalidering 'n kontinue een is wat betrekking het op die ontwikkeling van groter presisie en verfyning in die definiëring van sodanige konstruk en sy relevante gedragsvorme.

Samevattend kan die gevolgtrekking gemaak word dat die ondersoek daarop dui dat die doeltreffende hantering van teenstrydige en dubbelsinnige inligting een van die vermoëns is wat in 'n verskeidenheid van poste kan voorkom aangesien bedrewenheid in hierdie verband vereis dat die posbekleër 'n aanvaarbare intellektuele (verstandelike helderheid) vermoë sal hê waar intelligensie in hierdie bepaalde konteks dui op die vlak van abstraktheid en ingewikkeldheid in denke en redenering waartoe 'n persoon in staat is. Abstraktheid en ingewikkeldheid dui hier nie slegs op syferkundige en wiskundige probleme nie, maar op enige probleemstelling of situasie wat in die verrigting van arbeid ter sprake kom. Belangrik om in gedagte te hou is ook die feit dat die hantering van teenstrydige en dubbelsinnige inligting min verband met die ander gemete vermoëns toon en dit dus waarskynlik dui op die bestaan van 'n afsonderlike eienskap van werkverrigting.

Die vermoë om teenstrydige en dubbelsinnige inligting doeltreffend in 'n werksituasie te hanteer vereis verder ook dat die posbekleër oor die nodige sensories-kognitiewe 
oordeelsvermoë sal beskik wat in hierdie konteks dui op die vermoë om veralgemenings te kan maak, oordele te kan vel of besluite te neem op grond van sensoriese diskriminasie en kognitiewe evaluering. Oordeel en besluitneming is hier van toepassing maar dit word nie gebaseer op aanvoeling of intuïsie nie. Veel eerder word dit wat sensories en intellektueel waargeneem word gebruik as kriteria vir die neem van besluite.

Die vermoë om teenstrydige en dubbelsinnige inligting in die werksituasie te hanteer hang dus veel eerder saam met intellektuele vermoë en sensories kognitiewe oordeel as wat dit bepaal word deur sekere persoonlikheidseienskappe soos byvoorbeeld buigsaamheid vs. rigiditeit of dominansie vs. inskiklikheid.

\section{Aanbevelings}

Verdere navorsing behoort onderneem te word ten einde hierdie konstruk beter te omlyn. Guion (1965, p.129) stel dit baie duidelik wanneer hy sê dat: "Construct validity is not established with a single study but with the understanding that comes from a sizeable body of empirical data".

'n Area wat nie in hierdie studie ondersoek is nie, maar wat nagevors behoort te word, is hoedanig ambivalensie van houding en/of belangstelling hier ter sprake is. Uit die literatuurbeskrywing van sekere kognitiewe style blyk dit asof dit verband sou kan hou met die vermoë om teenstrydige en dubbelsinnige inligting te hanteer.

Die Posmandjie as meetinstrument skyn gesigs- sowel as inhoudsgeldigheid te hê. Meer navorsing ten opsigte van die voorspellingsgeldigheid daarvan behoort onderneem te word.

Die Posmandjie as meetinstrument word in die praktyk al meer gebruik. Die rede hiervoor is dat die inhoud daarvan werks-relevant is en dat dit gevolglik nie blootgestel is aan die bevraagtekening (veral in die VSA) en kritiek wat teen ander sielkundige meetinstrumente ingebring word nie. Die Posmandjie word byvoorbeeld veral ingespan as deel van takseersentrums om bestuurspotensiaal te identifiseer (Byham en Thornton, 1970) en verdere navorsing ten opsigte van die bruikbaarheid van die tegniek sou vir die personeelbestuurspraktyk tot voordeel wees. 


\title{
OPSOMMING
}

\begin{abstract}
Min informasie bestaan omtrent die hantering van teenstrydige en dubbelsinnige inligting as kritieke vermoë in vele werksituasies. Met hierdie ondersoek is daar gepoog om die konstruk te omlyn en aan ' $n$ empiriese verifiering te onderwerp. ' $n$ Meetinstrument (posmandjie) is ontwikkel om die hantering van teenstrydige en dubbelsinnige inligting te meet en is saam met ander meetinstrumente ter omlyning van die genoemde konstruk aan twee groepe proefpersone geadministreer. Daar is vasgestel dat hierdie vermoë verband hou met intellektuele vermoëns en sensories kognitiewe oordeel en nie met sekere persoonlikheids- en ander determinante van mens like gedrag nie en dat dit na alle waarskynlikheid dui op die bestaan van 'n afsonderlike werksvermoë of konstruk.
\end{abstract}

\section{VERWYSINGS}

Adorno, T.W., Frenkel-Brunswik, E., Levinson, D.J. \& Sanford, R.N. The Authoritarian Personality. New York: Harper, 1950.

Asher, J.J. \& Sciarrino, J.A. Realistic work sample tests: A review. Personnel Psychology, 1974, 27, 519-533.

Brown, R. Social Psychology. Collier MacMillan, 1965.

Byham, W.C. \& Thornton, G.C. Assessment centres, a new aid in management selection. Studies in Personnel Psychology, 1970, 3(2), 21-35.

Campion, J.E. Work sampling for personnel selection. Journal of Applied Psychology, 1972, $56,40-44$.

De Jager, L.C. Sielkundige diepte-oriëntasie as determinant van menslike gedrag met spesifieke verwysing na die beroepswêreld. Ongepubliseerde Doktorale proefskrif. Randse Afrikaanse Universiteit, 1979.

Guion, R.M. Personnel Testing. New York: McGraw-Hill, 1965.

Krech, D., Cruchfield, R.S. \& Ballachey, E.L. Individual in Society. Tokyo: McGraw-Hill, 1962.

Lätti, V.I. Aanleg, toetsing, keuring en plasing. People and Profits, 1977, 4(5), 46-52.

Marquardt, L.D. \& McCormick, E.J. Attribute ratings and profiles of the job elements of the Position Analysis Questionnaire (PAQ). Occupational Research Center, Purdue University, 1972 (Prepared for office of Naval Research under contract NR 152-231 Report 1).

Marquardt, L.D. \& McCormick, E.J. Component analysis of attribute data based on the Position Analysis Questionnaire (PAQ). Occupational Research Center, Purdue University, 1973 (Prepared for Office of Naval Research under contract NR 152-331 Report 2)..

McCormick, E.J., Jeaneret, P.R. \& Mecham, R.L. The development and background of the position analysis questionnaire. Occupational Research Center. Purdue University, 1969 (Prepared for office of Naval Research under contract NR - 1100 (28) Report 5).

Meyer, H.H. The validity of the in basket test as a measure of managerial performance.

Personnel Psychology, 1970, 23(3), 297-307. 
Miner, J.B. \& Miner, M.G. Personnel and Industrial Relations - A Managerial Approach. New York: MacMillan, 1977.

Munn, N.L. Psychology - The Fundamentals of Human Adjustment. London: Harrap, 1961.

Orpen, C. The Principles of Personnel Psychology. Kenwyn: Juta, 1979.

Perloff, M. A better alternative. Analysis, 1979, 39(2), 106-108.

Raubenheimer, I.v.W., Augustyn, J.C.D., De Villiers, W.S. Vertroulike navorsingsverslae. 1979 (Ongepubliseer).

Raubenheimer, I.v.W., Augustyn, J.C.D., De Villiers, W.S., Fick, L.J. Die Radef

Belangstellingsvraelys, Stellenbosch, 1978. (Ongepubliseer).

Tyler, L.E. The psychology of human differences. Englewood Cliffs N.J.: Prentice Hall, 1965.

Zaleznik, A. \& Moment, D. The dynamics of interpersonal behavior. New York: Wiley 1964. 